\title{
Metabolic engineering of Escherichia coli for the production of riboflavin
}

\author{
Zhenquan Lin ${ }^{1,2,3}$, Zhibo Xu ${ }^{1,2,3}$, Yifan $\mathrm{Li}^{1,2,3}$, Zhiwen Wang ${ }^{1,2,3^{*}}$, Tao Chen ${ }^{1,2,3^{*}}$ and Xueming Zhao ${ }^{1,2,3}$
}

\begin{abstract}
Background: Riboflavin (vitamin $B_{2}$ ), the precursor of the flavin cofactors flavin mononucleotide (FMN) and flavin adenine dinucleotide (FAD), is used commercially as an animal feed supplement and food colorant. E. coli is a robust host for various genetic manipulations and has been employed for efficient production of biofuels, polymers, amino acids, and bulk chemicals. Thus, the aim of this study was to understand the metabolic capacity of E. coli for the riboflavin production by modification of central metabolism, riboflavin biosynthesis pathway and optimization of the fermentation conditions.

Results: The basic producer RF01S, in which the riboflavin biosynthesis genes ribABDEC from E. coli were overexpressed under the control of the inducible trc promoter, could accumulate $229.1 \mathrm{mg} / \mathrm{L}$ of riboflavin. Further engineering was performed by examining the impact of expression of zwf (encodes glucose 6-phosphate dehydrogenase) and gnd (encodes 6-phosphogluconate dehydrogenase) from Corynebacterium glutamicum and pgl (encodes 6-phosphogluconolactonase) from E. coli on riboflavin production. Deleting pgi (encodes glucose-6-phosphate isomerase) and genes of Entner-Doudoroff (ED) pathway successfully redirected the carbon flux into the oxidative pentose phosphate pathway, and overexpressing the acs (encodes acetyl-CoA synthetase) reduced the acetate accumulation. These modifications increased riboflavin production to $585.2 \mathrm{mg} / \mathrm{L}$. By further modulating the expression of ribF (encodes riboflavin kinase) for reducing the conversion of riboflavin to FMN in RF05S, the final engineering strain RF05S-M40 could produce $1036.1 \mathrm{mg} / \mathrm{L}$ riboflavin in $\mathrm{LB}$ medium at $37^{\circ} \mathrm{C}$. After optimizing the fermentation conditions, strain RF05S-M40 produced $2702.8 \mathrm{mg} / \mathrm{L}$ riboflavin in the optimized semi-defined medium, which was a value nearly 12 -fold higher than that of RF01S, with a yield of $137.5 \mathrm{mg}$ riboflavin/g glucose.

Conclusions: The engineered strain RF05S-M40 has the highest yield among all reported riboflavin production strains in shake flask culture. This work collectively demonstrates that E. coli has a potential to be a microbial cell factory for riboflavin bioproduction.
\end{abstract}

\section{Background}

Riboflavin (vitamin $B_{2}$ ) is the universal precursor of flavin mononucleotide (FMN) and flavin adenine dinucleotide (FAD), both of which act as hydrogen carriers and are essential for the activity of a wide variety of metabolic enzymes in higher eukaryotes [1,2]. Riboflavin is synthesized by all plants, fungi and most bacteria, but not by higher animals including humans. So humans and animals must obtain riboflavin through dietary sources [3]. Traditionally, riboflavin was synthesized and produced by chemical

\footnotetext{
*Correspondence: zww@tju.edu.cn; chentao@tju.edu.cn

'Department of Biochemical Engineering, School of Chemical Engineering and Technology, Tianjin University, Tianjin 300072, People's Republic of China ${ }^{2}$ Key Laboratory of Systems Bioengineering, Ministry of Education, Tianjin University, Tianjin 300072, People's Republic of China

Full list of author information is available at the end of the article
}

procedures or microbial fermentation. Since chemical synthesis of riboflavin has many disadvantages such as high cost and energy wasting, the microbial fermentation method has been widely applied in industrial production.

Riboflavin biosynthesis has been studied in both grampositive and gram-negative bacteria, extensively in Bacillus subtilis and E. coli. Riboflavin is synthesized from one molecule of GTP and two molecules of ribulose 5-phosphate ( $\mathrm{Ru}-5-\mathrm{P})$ through a seven-step synthetic pathway, which is similar in all organisms (Figure 1) [4]. Riboflavin has been produced by the filamentous fungus Ashbya gossypii, the yeast Candida famata, and the bacterium B. subtilis, all of which have been developed by using a combined approach of classical mutagenesis and rational metabolic engineering $[3,5]$. Thus, the genetic background of these strains 


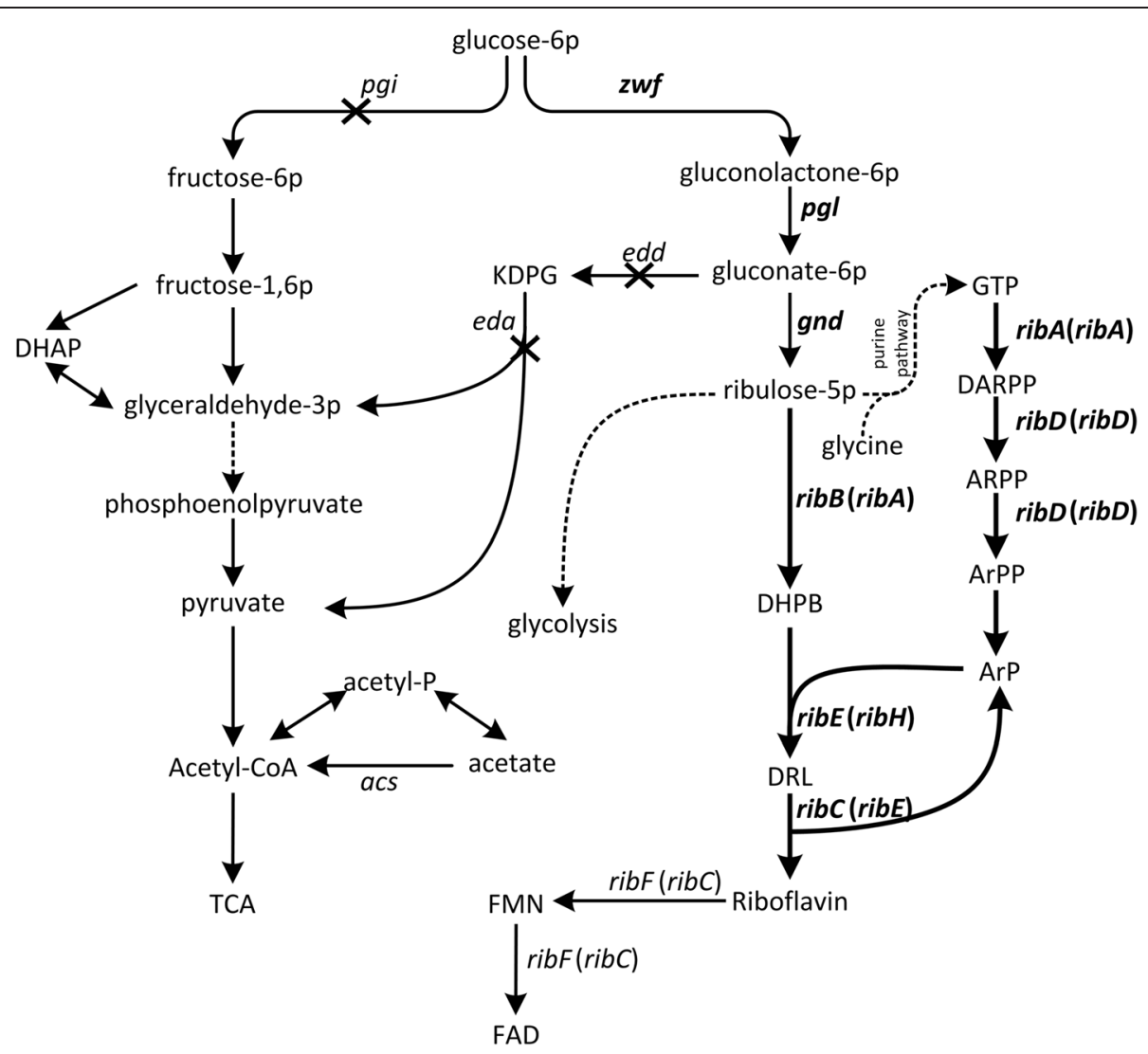

Figure 1 Schematic overview of the relevant pathways of riboflavin production and engineering strategies for riboflavin production. Bacillus subtilis gene names were bracketed. Dashed lines indicate multiple enzymatic steps. The bold lines indicate the overexpression of the corresponding genes. The $\times$ indicates the deletion of the corresponding genes. Enzymes encoded by the genes shown are: pgi, phosphoglucose isomerase; zwf, glucose 6-phosphate dehydrogenase; pgl, 6-phosphogluconolactonase; gnd, 6-phosphogluconate dehydrogenase; edd, phosphogluconate dehydratase; eda, multifunctional 2-keto-3-deoxygluconate 6-phosphate aldolase and 2-keto-4-hydroxyglutarate aldolase and oxaloacetate decarboxylase; ribA, GTP cyclohydrolase II; ribB, 3,4-dihydroxy-2-butanone 4-phosphate synthase; ribD, fused diaminohydroxyphosphoribosylaminopyrimidine deaminase/ 5-amino-6-(5-phosphoribosylamino)uracil reductase; ribE, 6,7-dimethyl-8-ribityllumazine synthase; ribC, riboflavin synthase; ribF, bifunctional riboflavin kinase/FMN adenylyltransferase; acs, acetyl-CoA synthetase. The abbreviated metabolic intermediates are: KDPG, 2-keto-3-deoxy-6-phospho-D-gluconate; GTP, guanosine-triphosphate; DARPP, 2,5-diamino-6-ribosylamino-4(3H)-pyrimidinone 5'-phosphate; ARPP, 5-amino-6-(5'-phosphoribitylamino)uracil; ArPP, 5-amino-6-(5-phospho-D-ribitylamino)uracil; ArP, 5-amino-6-(D-ribitylamino)uracil; DHPB, 3,4-dihydroxy-2-butanone-4-P; DRL, 6,7-dimethyl-8-(1-D-ribityl) lumazine; FMN, riboflavin-5'-phosphate; FAD, flavin adenine dinucleotide; TCA, Tricarboxylic acid cycle.

was usually complicated and the mechanism of riboflavin overproduction was not fully elucidated.

In a series of previous reports, a numbers of conceivable strategies were carried out to develop B. subtilis as a riboflavin-producing strain after selection for resistance to different antimetabolites. In $B$. subtilis, the riboflavin production was increased by amplifying copies of rib operon or ribA gene [6,7], or by enhancing the energy generation and reducing the maintenance metabolism [8-10]. Other efforts focused on modulating precursor metabolites supply by increasing the carbon flow through the pentose phosphate pathway (PP pathway) [11-14], by deregulating the gluconeogenesis flux via inactivating the $\operatorname{ccpN}[15]$, or by enhancing the flux of purine synthesis pathway $[16,17]$.
E. coli has been employed for efficient production of biofuels, amino acids, and bulk chemicals [18-20]. Although wild type $E$. coli does not accumulate riboflavin under natural conditions, it may be an efficient host for the production of riboflavin due to its clear genetic background, fast-growing, low maintenance metabolism, and the presence of convenient metabolic engineering tools. Thus, the aim of this study was to understand the metabolic capacity of $E$. coli for the production of riboflavin by modification of central metabolism, riboflavin biosynthesis pathway and optimization of the fermentation conditions.

In this study, the riboflavin synthetic pathway from $E$. coli and B. subtilis was constructed and compared in E. coli MG1655. Then, we examined the impact of overexpressing 
mutation type of $z w f$ and gnd genes from C. glutamicum and $p g l$ from E. coli on riboflavin production. Third, the glycolysis and ED pathway were modified to reroute carbon flux to the PP pathway for improving the riboflavin synthesis. Fourth, the acetate accumulation was reduced by overexpressing the acs gene. Finally, riboflavin production was significantly increased by modulating the expression of ribF. We also optimized the fermentation conditions for the riboflavin production. The final recombinant strain RF05S-M40 produced $2702.8 \mathrm{mg} / \mathrm{L}$ riboflavin with a yield of $137.5 \mathrm{mg}$ riboflavin/g glucose under the optimized batch fermentation condition.

\section{Results and discussion}

\section{Construction of riboflavin synthetic pathway}

Previous researches indicated that overexpression of the genes of the riboflavin synthetic pathway contributed to the efficient production of riboflavin. In B. subtilis, introduction of multiple copies of rib operon into the chromosome resulted in improving the riboflavin production [7]. In Pichia pastoris, overexpression of the riboflavin biosynthetic pathway caused riboflavin production increased to $175 \mathrm{mg} / \mathrm{L}$ riboflavin although the wild type $P$. pastoris did not accumulate riboflavin [21]. In C. famata, overexpressing the gene related to the riboflavin production significantly increased riboflavin production [22].
As shown in Figure 1, the genes of the riboflavin synthetic pathway (ribA, ribB, ribD, ribE, ribC) from E. coli were assembled into an artificial operon called EC10, under the control of the inducible trc promoter (Ptrc). Since the enzymatic activity of GTP cyclohydrolase II and 3, 4-dihydroxy-2-butanone 4-phosphate synthase played a critical role in riboflavin biosynthesis [21-23], the corresponding encoding genes ribA and ribB from $E$. coli were rearranged as the first and second genes in the operon. To test the dosage effect of the operon on riboflavin production, EC10 was inserted into plasmids with different copy numbers, generating p5C-EC10, p15C-EC10 and p20CEC10, which have pSC101, p15A and pBR322 replication origin, respectively. Wild type E. coli MG1655, harboring p5C-EC10, p15C-EC10 and p20C-EC10, produced $50.5 \pm 1.2,88.6 \pm 7.0$ and $229.1 \pm 5.7 \mathrm{mg} / \mathrm{L}$ riboflavin (Figure 2), respectively. These results indicated that higher copy number of riboflavin synthetic genes was beneficial for riboflavin overproduction, which was in accordance with previously published results $[3,7]$.

The traditional gene names are different in $E$. coli and $B$. subtilis (Figure 1). For consistency, we use the $E$. coli gene names throughout. Thus, the B. subtilis ribA, ribD, ribH, $r i b E$ genes are renamed to $r i b B / A$, $r i b D$, $r i b E$, $r i b C$, respectively (Figure 1$)$. To test the productivity of the riboflavin pathway from B. subtilis, plasmid p20C-BSrib was constructed by directly inserting the native rib operon

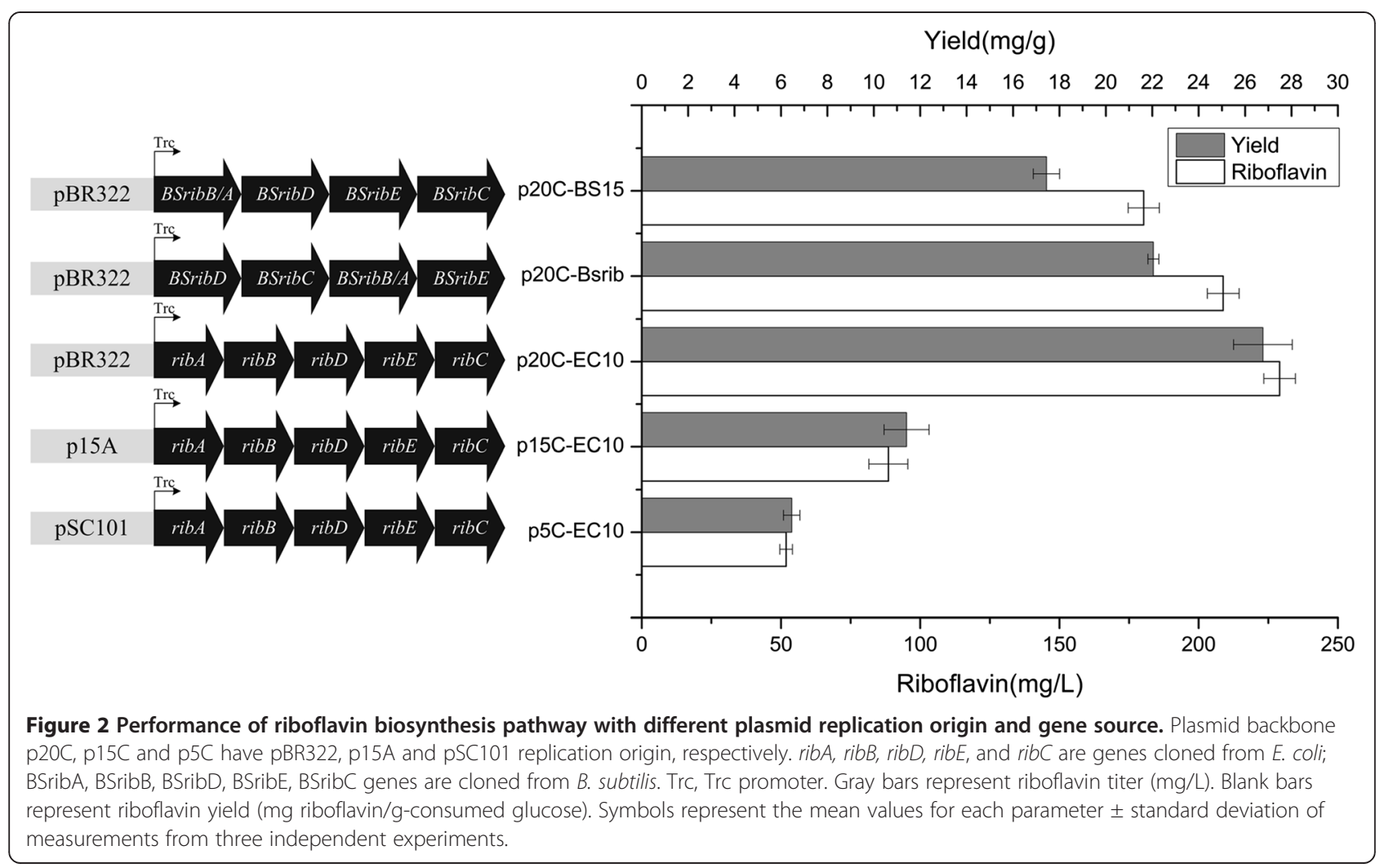


from the genome of $B$. subtilis into p20C. MG1655 harboring p20C-BSrib produced $200.5 \pm 7.1 \mathrm{mg} / \mathrm{L}$ riboflavin (Figure 2). Moreover, to construct a synthetic operon devoid of native regulation, the riboflavin pathway genes from $B$. subtilis were individually amplified, rearranged according to the order in the metabolic pathway (BSrib $(B / A)$ $D E C$ ), and assembled into p20C, creating plasmid p20CBS15. E. coli MG1655 harboring p20C-BS15 produced $180.3 \pm 5.6 \mathrm{mg} / \mathrm{L}$ riboflavin (Figure 2), which was slightly lower than that of p20C-BSrib. Moreover, the activities of key enzymes of riboflavin synthesis, GTP cyclohydrolase II and riboflavin synthase in MG1655(p20C-BS15) were lower than that in MG1655(p20C-BSrib) (Table 1). This phenomenon may be due to that the internal promoters of native $r i b$ operon were removed after rearranging the gene order [24], which led to a decrease in the expression level of key genes $r i b B / A$ and $r i b C$. Among all the tested $r i b$ gene expressing plasmids, p20C-EC10 showed the highest riboflavin productivity. Thus, strain RF01S (MG1655 harboring p20C-EC10) was selected for further engineering.

\section{Effects of zwf, gnd, and pgl overexpression on riboflavin production}

Ribulose 5-phosphate is an important precursor for riboflavin biosynthesis. Overexpressing the genes of oxidative PP pathway increased the ribulose 5-phosphate supply and improved riboflavin production by $31 \%$ in B. subtilis [13]. Mutant genes $z w f^{(A 243 T)}$ [25] and $g n d^{(S 361 F)}$ [26] from C. glutamicum, which encode glucose 6-phosphate dehydrogenase and 6-phosphogluconate dehydrogenase with removal of feedback inhibition, were co-overexpressed by introducing plasmid p15Trc-zg into RF01S. As shown in Table 2, the enzyme activities of glucose 6-phosphate dehydrogenase and 6-phosphogluconate dehydrogenase were significantly increased. However, the resulting strain showed only a slight increase in riboflavin titer and yield, compared to that harboring p15Trc (Table 2). Due to the low endogenous activity of 6-phosphogluconolactonase in E. coli $[27,28]$, we further overexpressed pgl (encoding 6phosphogluconolactonase) from $E$. coli along with $z w f$ and gnd by transforming p15Trc-zgp into RF01S, which led to an increase of $18.9 \%$ and $38.7 \%$ in riboflavin titer and

Table 1 Activities of GTP cyclohydrolase II and Riboflavin synthase

\begin{tabular}{lll}
\hline Strain/Plasmid & \multicolumn{2}{l}{ Enzyme activities (nmol/min/mg protein) } \\
\cline { 2 - 3 } & GTP cyclohydrolase Il $^{\mathbf{a}}$ & Riboflavin synthase $^{\mathbf{b}}$ \\
\hline E. coli MG1655/p20C-EC10 & $8.6 \pm 0.4$ & $14.3 \pm 1.6$ \\
E. coli MG1655/p20C-BSrib & $6.4 \pm 0.3$ & $10.9 \pm 0.4$ \\
E. coli MG1655/p20C-BS15 & $6.3 \pm 0.2$ & $9.6 \pm 0.4$
\end{tabular}

${ }^{\mathrm{a}}$ One unit of enzyme activity catalyzes the formation of $1 \mathrm{nmol}$ of 2,5-diamino6-ribosylamino-4(3H)-pyrimidinone 5'-phosphate per min. ${ }^{b}$ One unit of enzyme activity catalyzes the formation of $1 \mathrm{nmol}$ of riboflavin per min. yield, compared to that harboring p15Trc (Table 2). However, compared to strain RF01S, overexpressing PP pathway genes did not significantly increase the riboflavin production, possibly because of the complex regulation of central metabolic pathway [29] and a high metabolic burden of heterologous protein production [30].

\section{Disruption of pgi for improving riboflavin production}

Based on the results of overexpressing the genes of PP pathway, the strategy of eliminating competitive pathway for redirecting the carbon flux into the oxidative PP pathway was employed to improve the riboflavin production. The disruption of pgi encoding phosphoglucose isomerase resulted in a blocked entry into glycolysis and compelled glucose 6-phosphate to be metabolized exclusively through PP pathway [31]. Thus, we disrupted pgi in MG1655, creating RF02. RF02 harboring p20C-EC10 (RF02S) accumulated $394.8 \pm 19.6 \mathrm{mg} / \mathrm{L}$ riboflavin, which was $72.4 \%$ higher than that of the reference strain RF01S (Table 3). In accord with previous studies, the $\Delta p g i \mathrm{mu}-$ tant strains showed strongly reduced glucose uptake rates and maximum specific growth rate [32]. One possible reason for this phenomenon was that the $\Delta p g i \mathrm{mu}-$ tation would result in high glucose 6-phosphate pool and led to the rapid degradation of ptsG mRNA, an important member of the PTS transport systems, which would decrease the glucose uptake capacity [33]. Moreover, the $\Delta p g i$ mutation also diminishes the supply of PEP needed for PTS-mediated uptake of glucose and decreases the growth rate [34].

\section{Disruption of edd and eda for improving riboflavin production}

The ED pathway has been shown to be inactive with glucose as the carbon source in wild-type E. coli [35], but it was activated in the pgi mutant strain [31]. Previous studies indicated that glucose was mainly metabolized through PP pathway and partially through ED pathway after pgi was disrupted [36].

The edd and eda transcription levels in the $\Delta p g i$ strain RF02 were compared with parent strain MG1655 through RT-qPCR analysis. Consistent with previously research [37], the transcript abundance of $e d d$ and eda increased 2.21-fold and 2.36-fold in RF02, respectively, which indicated that ED pathway was up-regulated in $\Delta p g i$ strain. Thus, edd and eda were disrupted in RF02 for further increasing the flux from 6-phosphogluconate to $\mathrm{Ru}-5-\mathrm{P}$, resulting in strain RF03. RF03 harboring p20C-EC10 (strain RF03S) produced $559.88 \pm 8.99 \mathrm{mg} / \mathrm{L}$ riboflavin, which increased by $41.8 \%$ compared to that of RF02S (Table 3). These results suggested that further increasing riboflavin precursors can be achieved via disrupting ED pathway in the pgi mutation strain. 
Table 2 Effect of overexpressing pentose phosphate pathway genes on riboflavin production and enzyme activities

\begin{tabular}{|c|c|c|c|c|c|}
\hline \multirow[t]{2}{*}{ Strain/plasmid } & \multirow[t]{2}{*}{$0 D 600^{a}$} & \multirow{2}{*}{$\begin{array}{l}\text { Riboflavin } \\
\text { (mg/L) }\end{array}$} & \multirow{2}{*}{$\begin{array}{l}\text { Riboflavin } \\
\text { yield }(\mathrm{mg} / \mathrm{g})^{\mathrm{b}}\end{array}$} & \multicolumn{2}{|c|}{ Enzyme activity (nmol/min/mg protein) } \\
\hline & & & & G6PDH $^{d}$ & $6 \mathrm{PGDH}^{\mathrm{d}}$ \\
\hline RF01S/p15Trc & $3.8 \pm 0.1$ & $192.1 \pm 7.3$ & $23.0 \pm 0.9$ & $111.5 \pm 11.5$ & $119.1 \pm 8.4$ \\
\hline RF01S/p15Trc-zg & $3.0 \pm 0.1$ & $197.4 \pm 9.2$ & $24.2 \pm 1.4$ & $203.6 \pm 18.5$ & $174.7 \pm 14.2$ \\
\hline RF01S/p15Trc-zgp & $3.1 \pm 0.1$ & $228.4 \pm 0.9$ & $31.9 \pm 1.3$ & $199.0 \pm 20.0$ & $177.1 \pm 17.6$ \\
\hline
\end{tabular}

${ }^{\mathrm{a}} \mathrm{OD}_{600}$ is the final optical density of the culture.

${ }^{\mathrm{b}} \mathrm{mg} / \mathrm{g}$ : $\mathrm{mg} / \mathrm{g}$-consumed glucose.

Batch cultures of recombinant strains were carried out in LB medium containing $10 \mathrm{~g} / \mathrm{L}$ glucose at $37^{\circ} \mathrm{C}$ as described in methods. Standard deviations were calculated from the results of three independent experiments.

${ }^{\mathrm{C}}$ One unit of the enzyme activity was defined as the amount catalyzing the formation of $1 \mathrm{nmol}$ of NADPH per min. Results are the mean values of three measurements.

${ }^{\mathrm{d}} 6 \mathrm{PGDH}, 6$-phosphogluconate dehydrogenase; G6PDH, glucose 6-phosphate dehydrogenase.

\section{Effect of the acs promoter insertion on riboflavin production}

Acetate, which led to growth retardation, was the main byproduct of these recombinant strains. Thus, the strategy of overexpressing the acs gene encoding acetyl-CoA synthetase was selected to reduce acetate secretion. The trc promoter was inserted in the upstream of acs gene in RF03, resulting in strain RF05. RT-qPCR analysis showed that the expression of acs gene in RF05S (RF05 harboring p20C-EC10) increased 4.80-fold compared with RF03S, indicating successful overexpression of acs gene. RF05S produced $585.2 \pm 13.6 \mathrm{mg} / \mathrm{L}$ riboflavin with a yield of $59.30 \mathrm{mg} / \mathrm{g}$ glucose, which did not change significantly compared to RF03S (Table 3). However, the acetate production decreased from $4.0 \mathrm{~g} / \mathrm{l}$ to $1.5 \mathrm{~g} / \mathrm{L}$ in strain RF05S, which was in accordance with the results presented by Lin et al. [38].

\section{Modulating the expression ribF for enhanced riboflavin production}

According to previous studies, introducing a mutation in $r i b C$ gene (encoding flavokinase/flavin adenine dinucleotide synthetase) in B. subtilis could reduce enzymatic activity and resulted in riboflavin overproduction in the engineering strains [39]. The ribC mutation of B. subtilis also reduced the synthesis of FMN, which is a negative regulatory factor of rib operon transcription [40]. In E. coli, these enzymes were encoded by ribF, which is an essential gene for strain growth [41]. Therefore, we speculate that reducing the expression level ribF might reduce the conversion of riboflavin to FMN/FAD and increase riboflavin production.

To modulate the expression of ribF, we designed a library of RBS sequences with varied strengths weaker than that of the native ribF RBS using RBS calculator [42]. Then, the native RBS of ribF on the chromosome of RF05S was replaced with the designed RBS library using the method described in methods. Forty three mutants were selected and transformed with p20C-EC10 to screen for enhanced riboflavin producer. Riboflavin production of the selected strains was measured after $48 \mathrm{~h}$ cultivation in $\mathrm{LB}$ medium with $10 \mathrm{~g} / \mathrm{L}$ glucose at $37^{\circ} \mathrm{C}$ in flasks. The majority of the selected strains exhibited increased riboflavin production compared with the parent strain (Figure 3), which demonstrated that modulating ribF expression could efficiently increase riboflavin production. Strain RF05S-M40 produced $1036.1 \pm 54.6 \mathrm{mg} / \mathrm{L}$ riboflavin, which was the highest among all selected strains, and was $77.0 \%$ higher than that of RF05S. Representative profiles of riboflavin production, biomass accumulation and glucose consumption for the strain RF05SM40 were shown in Figure 4A. Flavokinase activity in cell-free extracts of RF05S was about $1.45 \pm 0.09 \mathrm{nmol} /$ $\mathrm{min} / \mathrm{mg}$ protein, while that of RF05S-M40 was about $0.94 \pm 0.04 \mathrm{nmol} / \mathrm{min} / \mathrm{mg}$ protein, indicating that the expression level of flavokinase was decreased by modulating the RBS of ribF and this reduced expression contributed much to riboflavin overproduction.

Table 3 Riboflavin production of the various strains constructed in the study

\begin{tabular}{|c|c|c|c|c|c|}
\hline Strain & OD600 & Biomass $(g / L)^{b}$ & Riboflavin (mg/L) & Riboflavin yield $(\mathrm{mg} / \mathrm{g})^{c}$ & Specific productivity (mg-RF/g-DCW/h) \\
\hline RF02S & $5.4 \pm 0.3$ & $2.0 \pm 0.1$ & $394.8 \pm 9.6$ & $39.9 \pm 1.1$ & $5.1 \pm 0.2$ \\
\hline RF03S & $5.2 \pm 0.4$ & $1.9 \pm 0.1$ & $559.9 \pm 8.9$ & $59.9 \pm 0.8$ & $8.2 \pm 0.3$ \\
\hline RF05S & $4.9 \pm 0.2$ & $1.8 \pm 0.1$ & $585.2 \pm 13.6$ & $59.3 \pm 1.3$ & $8.6 \pm 0.2$ \\
\hline
\end{tabular}

${ }^{\mathrm{a}} \mathrm{OD}_{600}$ is the final optical density of the culture.

${ }^{\mathrm{b}}$ The average cell dry weight for all of the strains was $0.38 \mathrm{~g} / \mathrm{L}$ per optical-density (OD600) unit of culture.

${ }^{\mathrm{c}} \mathrm{mg} / \mathrm{g}$ : $\mathrm{mg}$ riboflavin/g-consumed glucose.

Batch cultures of recombinant strains were carried out in LBG medium (LB with $10 \mathrm{~g} / \mathrm{L}$ glucose) at $37^{\circ} \mathrm{C}$ as described in methods. Standard deviations were calculated from the results of three independent experiments. 


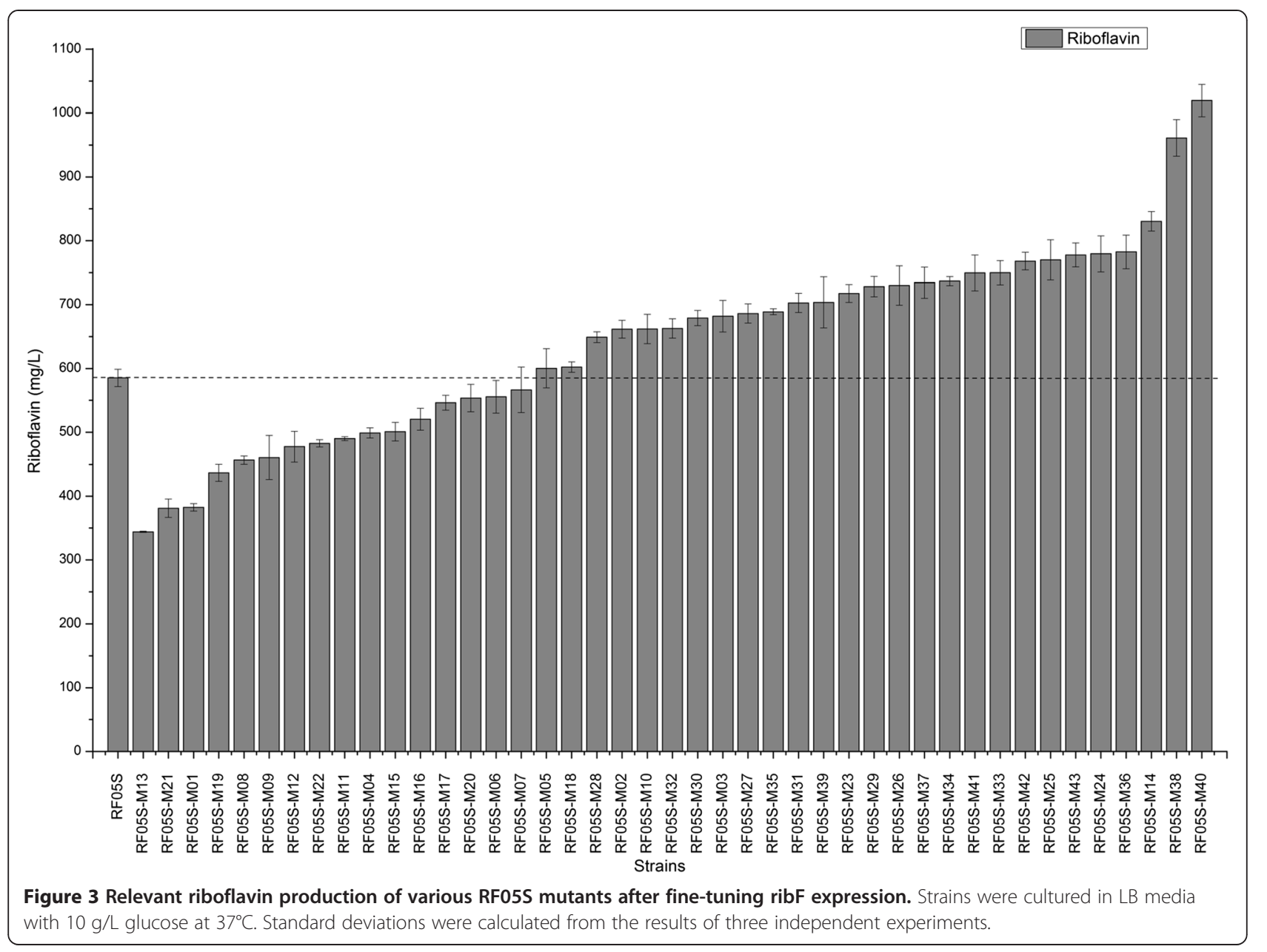

\section{Optimization of fermentation conditions for riboflavin production}

To optimize fermentation condition, we investigated the effect of different culture temperatures on riboflavin production. Changing the fermentation temperature from $37^{\circ} \mathrm{C}$ to $31^{\circ} \mathrm{C}$ increased riboflavin titer to $1507.0 \pm 56.8 \mathrm{mg} / \mathrm{L}$ from $1036.1 \pm 54.6 \mathrm{mg} / \mathrm{L}$ (Figure 4B). Many factors may have contributed to the enhanced production. For example, growth temperature was reported to influence not only recombinant gene expression and protein folding, but also the global metabolism of the strains [43]. In addition, low growth temperature was reported to stabilize the recombinant proteins and improve the plasmid stability [44].

We further evaluated the riboflavin production of RF05S-M40 in semi-synthetic medium. Two different semisynthetic medium formulations, M9 minimal medium and MS medium, were tested with different concentration of yeast extract at $37^{\circ} \mathrm{C}$ or $31^{\circ} \mathrm{C}$ (Table 4). When cells were cultivated in $\mathrm{M} 9$ minimal medium with $1 \mathrm{~g} / \mathrm{L}$ yeast extract at $37^{\circ} \mathrm{C}$, cell growth was severely hampered (OD 600 of 4), leading to a titer of $271.8 \pm 4.9 \mathrm{mg} / \mathrm{L}$ riboflavin (Table 4). Switching to another defined semi-synthetic medium (MS medium) led to much higher titers (Table 4). Using MS medium with $5 \mathrm{~g} / \mathrm{L}$ yeast extract as culture medium exhibited the highest productivity in shake flask culture at $31^{\circ} \mathrm{C}$. Optimization of the composition of MS medium further increased riboflavin production. Detailed composition of the optimized MS medium and riboflavin production profile were shown in Additional file 1: Table S2. Statistical analysis indicated that the adding of glycine in the medium contributed significantly to riboflavin overproduction. The reason for the increase in the riboflavin production might be that the supplement of glycine, which is an important purine precursor and is incorporated into the riboflavin molecule, enhanced the availability of GTP and thus improved the riboflavin production [45]. Similar phenomenon has been reported in A. gossypii and C. famata [46].

The time profiles of cell growth, glucose consumption and riboflavin production in the non-optimized medium and the optimized medium were shown in Figure 5. A maximal cell density was attained and residual glucose was almost exhausted after $60 \mathrm{~h}$ culture. A maximal riboflavin production reached $2702.8 \pm 89.9 \mathrm{mg} / \mathrm{L}$ using the optimized 


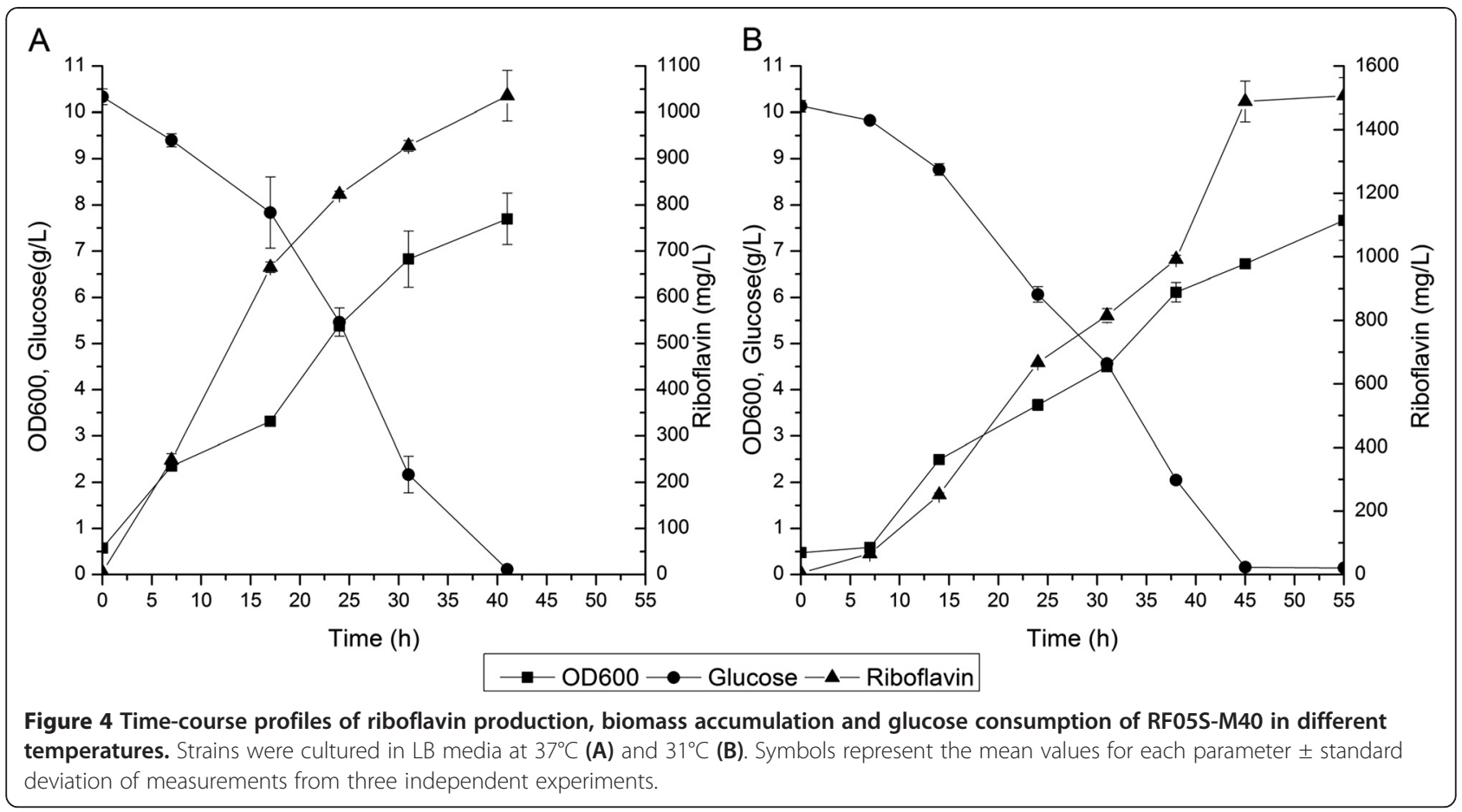

medium with a yield of $137.5 \mathrm{mg}$ riboflavin/g glucose in shake flask cultivation, which was 2-fold higher than that of non-optimized medium. The final titer and specific production rates of RF05S-M30 were still lower than that of the industrial producers such as A. gossypii, C. famata, B. subtilis, and Corynebacterium ammoniagenes, which up to $20 \mathrm{~g} / \mathrm{L}$ riboflavin can be reached with specific production rates of $20.7 \mathrm{mg} / \mathrm{g} \mathrm{CDW} / \mathrm{h}$ in industrial fed-batch production processes $[5,13,47]$. However, the yields of these industrial producers were lower than that of the recombinant $E$. coli (e.g. 0.138 for RF05S-M40 versus 0.100 g riboflavin/g glucose for C. famata [22,47]). In addition, the specific glucose uptake rate of RF05S-M40 was still very low. Therefore, improving the glucose uptake rate could be an effective approach to further improving riboflavin production in RF05S-M40. Moreover, several published reports have shown that enhancing the availability of GTP increased the production of in B. subtilis and A. gossypii $[16,17,48,49]$, and thus further engineering the purine pathway might be a possible target for enhancing riboflavin

Table 4 Riboflavin production of RF05S-M40 in different cultural conditions

\begin{tabular}{|c|c|c|c|c|c|c|c|c|}
\hline Medium & Glucose (g/L) & Temperature $\left({ }^{\circ} \mathrm{C}\right)$ & Yeast extract (g/L) & $0 D 600^{a}$ & Biomass $^{b}(g / L)$ & Riboflavin (mg/L) & $\begin{array}{l}\text { Riboflavin } \\
\text { yield }(\mathrm{mg} / \mathrm{g})^{\mathrm{c}}\end{array}$ & $\begin{array}{l}\text { Specific productivity } \\
\text { (mg-RF/g-DCW/h) }\end{array}$ \\
\hline M9 & \multirow{10}{*}{$10^{\mathrm{d}}$} & 37 & 1 & $4.1 \pm 0.2$ & $1.6 \pm 0.1$ & $271.8 \pm 4.8$ & $66.4 \pm 8.6$ & $3.6 \pm 0.2$ \\
\hline M9 & & 37 & 3 & $7.0 \pm 0.1$ & $2.7 \pm 0.1$ & $289.5 \pm 7.9$ & $25.2 \pm 0.8$ & $2.3 \pm 0.1$ \\
\hline M9 & & 37 & 5 & $6.8 \pm 0.1$ & $2.7 \pm 0.1$ & $532.4 \pm 24.9$ & $50.7 \pm 0.6$ & $4.3 \pm 0.2$ \\
\hline MS & & 37 & 1 & $6.4 \pm 0.1$ & $2.4 \pm 0.1$ & $702.4 \pm 17.4$ & $66.0 \pm 0.7$ & $6.1 \pm 0.2$ \\
\hline MS & & 37 & 3 & $6.3 \pm 0.2$ & $2.4 \pm 0.1$ & $811.2 \pm 43.8$ & $79.7 \pm 2.3$ & $7.1 \pm 0.5$ \\
\hline MS & & 37 & 5 & $7.7 \pm 0.3$ & $2.9 \pm 0.1$ & $847.4 \pm 38.0$ & $82.7 \pm 3.2$ & $6.1 \pm 0.4$ \\
\hline M9 & & 31 & 5 & $7.7 \pm 0.2$ & $2.9 \pm 0.1$ & $892.5 \pm 23.1$ & $84.3 \pm 3.8$ & $6.4 \pm 0.3$ \\
\hline MS & & 31 & 1 & $6.5 \pm 0.2$ & $2.1 \pm 0.1$ & $577.6 \pm 11.4$ & $66.5 \pm 1.9$ & $4.9 \pm 0.2$ \\
\hline MS & & 31 & 3 & $7.3 \pm 0.2$ & $2.8 \pm 0.1$ & $907.7 \pm 12.8$ & $93.1 \pm 2.3$ & $6.8 \pm 0.2$ \\
\hline MS & & 31 & 5 & $7.6 \pm 0.2$ & $2.9 \pm 0.1$ & $1204.1 \pm 40.4$ & $120.6 \pm 5.4$ & $8.7 \pm 0.4$ \\
\hline
\end{tabular}

${ }^{\mathrm{a}} \mathrm{OD}_{600}$ was the final optical density of the culture.

${ }^{\mathrm{b}}$ The average cell dry weight for all of the strains was $0.38 \mathrm{~g} / \mathrm{L}$ per optical-density (OD600) unit of culture.

${ }^{\mathrm{c}} \mathrm{mg} / \mathrm{g}$ : $\mathrm{mg}$ riboflavin/g-consumed glucose.

${ }^{d}$ Batch cultures of RF05S-M40 was carried out in modified M9 or MS containing $10 \mathrm{~g} / \mathrm{L}$ glucose at $31^{\circ} \mathrm{C}$ or $37^{\circ} \mathrm{C}$. Standard deviations were calculated from the results of three independent experiments. 


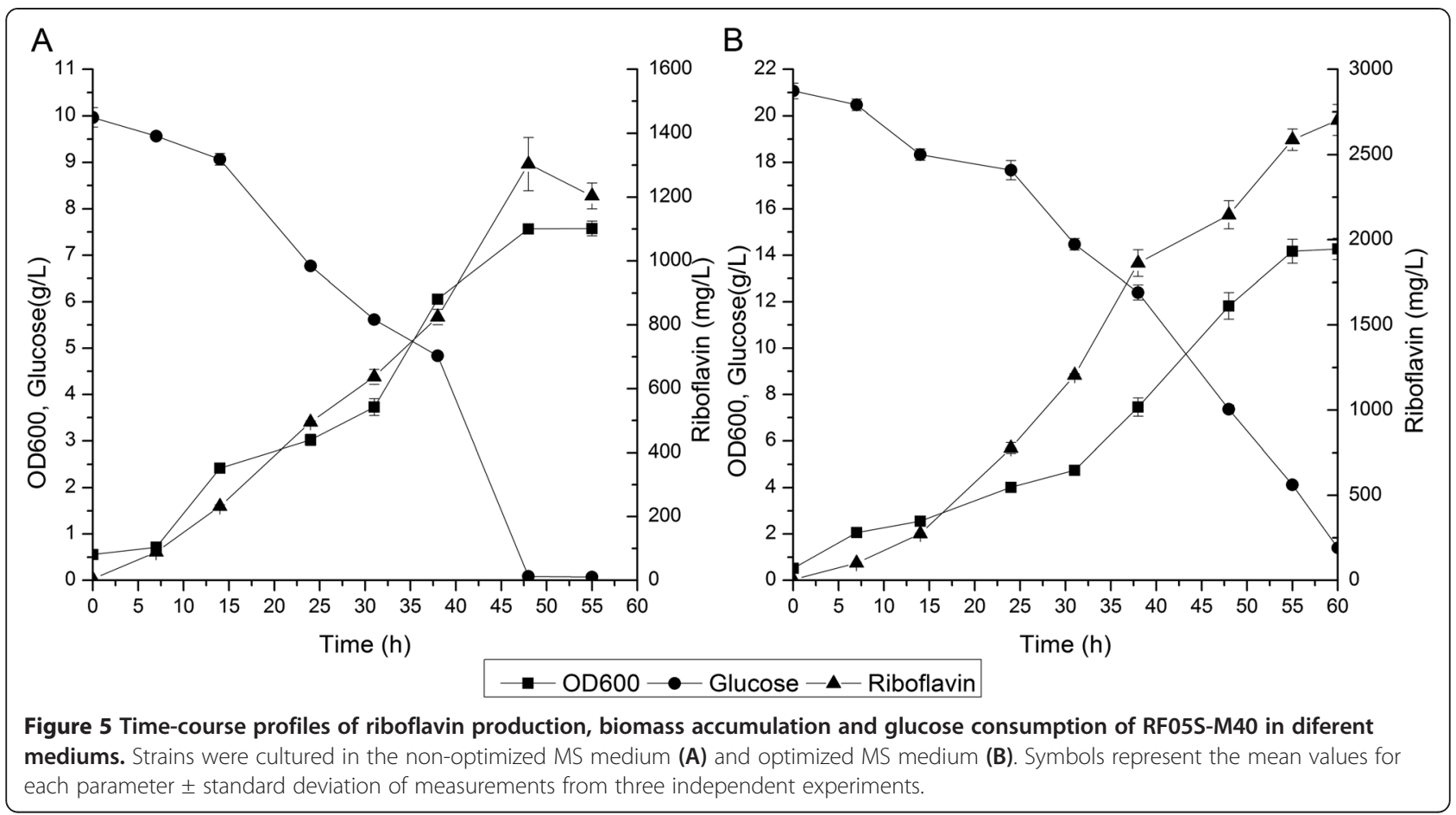

production. In addition, compared with previous studies [47], the fermentation strategy used in our research is much rougher. The riboflavin titer and productivity of the strain constructed in this work could be further increased by fed-batch fermentation optimization.

\section{Conclusions}

For the first time, we constructed a genetically defined riboflavin producing E. coli strain. Riboflavin synthetic pathway, PP pathway, central metabolic pathways, and riboflavin consumption pathway were systematically engineered for direct and efficient conversion of glucose to riboflavin. The E. coli strain RF05S-M40 has the highest yield among all reported riboflavin production strains in shake flask culture. This work also demonstrates that $E$. coli has a potential to be a host for riboflavin bioproduction.

\section{Methods}

Strain, medium, and cultivation condition

E. coli K-12 MG1655 (Coli Genetic Stock Center) was selected for engineering of the basic riboflavin-producing strains using a unique gene manipulate method. All strains used in this study are summarized in Table 5. E. coli DH5 $\alpha$ was used for the propagation of vector DNA. During strain construction, cultures were grown at $30^{\circ} \mathrm{C}$ or $37^{\circ} \mathrm{C}$ in Luria-Bertani (LB) broth (per liter: $10 \mathrm{~g}$ tryptone, $5 \mathrm{~g}$ yeast extract, $10 \mathrm{~g}$ sodium chloride) and supplemented with antibiotics as appropriate.

\section{Plasmid construction}

For the construction of p5C-EC10, p15C-EC10 and p20CEC10 plasmids, structural genes, including $r i b A, r i b B, r i b D$, ribE, and ribC, were amplified by PCR with oligonucleotide primers FuECribA-F, FuECribA-R, FuECribB-F, FuECribBR, FuECribD-F, FuECribD-R, FuECribE-F, FuECribE-R, FuECribC-F, and FuECribC-R using the genomic DNA of E. coli MG1655 as templates. The five fragments, were spliced by overlapping extension (SOE)-PCR [50], constructing E. coli rib operon EC10, which was then

Table 5 Strains used in this study

\begin{tabular}{|c|c|c|}
\hline Strain & Characteristics & Source \\
\hline Escherichia coli DH5a & $\begin{array}{l}\text { Coli Genetic Stock Center strain } \\
\text { (CGSC) No. } 12384\end{array}$ & $\operatorname{CGSC}^{a}$ \\
\hline E. coli MG1655 & $\begin{array}{l}\text { Coli Genetic Stock Center strain } \\
\text { (CGSC) No. } 7740\end{array}$ & CGSC \\
\hline Bacillus subtilis 168 & Wild type & Lab collection \\
\hline RF01S & $\begin{array}{l}\text { E. coli MG1655 containing } \\
\text { p20C-EC10 }\end{array}$ & This study \\
\hline RF02 & E. coli MG1655, $\Delta p g i$ & This study \\
\hline RF02S & RF02containing p20C-EC10 & This study \\
\hline RF03 & E. coli MG1655, $\Delta p g i, \Delta e d d, \Delta e d a$ & This study \\
\hline RF03S & RF03 containing p20C-EC10 & This study \\
\hline RF05 & $\begin{array}{l}\text { E. coli MG1655, } \Delta p g i, \Delta e d d, \Delta e d a, \\
\text { Ptrc-acs }\end{array}$ & This study \\
\hline RF05S & RF05 containing p20C-EC10 & This study \\
\hline
\end{tabular}

${ }^{a}$ Coli Genetic Stock Center. 
cloned into p5C, p15C, p20C between the EcoRI and HindIII restriction sites. A fragment BSrib containing the riboflavin operon from $B$. subtilis was amplified with oligonucleotide primers BSrib-F/BSrib-R and cloned into p20C between the EcoRI and BamHI restriction sites, creating plasmid p20C-BSrib. To construct p20C-BS15 plasmid, structural genes, including BDribA, BSribD, BSribH, BSribE, were amplified by PCR with oligonucleotide primers FuBSribA-F, FuBSribA-R, FuBSribD-F, FuBSribD$R$, FuBSribH-F, FuBSribH-R, FuBSribE-F and FuBSribE- $R$ using the genomic DNA of B. subtilis 168 as templates. The four fragments were spliced by SOE-PCR, constructing BS15. This was then cloned into p20C, obtaining the expressing plasmid p20C-BS15. Plasmids used were listed in Table 6.

For the construction of p15Trc-zg, zwf ${ }^{(\mathrm{A} 243 \mathrm{~T})}$ and gnd ${ }^{(\mathrm{S} 361 \mathrm{~F})}$ from C. glutamicum were firstly cloned in a p15A origin vector under the control of Ptrc individually by CPEC [51] with primer sets p15Trc-1BF, p15Trc-1BR, p15Trc-zwfF, p15Trc-zwfR, p15Trc-gndF, p15Trc-gndR respectively. Then, the $z w f^{(\mathrm{A} 243 \mathrm{~T})}$ and $g n d^{(\mathrm{S} 361 \mathrm{~F})}$ genes from C. glutamicum and $\mathrm{pgl}$ gene from E. coli were assembled into a p15A origin vector under the control of Ptrc by CPEC, obtaining plasmid p15Trc-zgp. All primers were listed in Additional file 1: Table S1, and plasmids constructed were listed in Table 6.

\section{Genome engineering: gene deletion, replacement, and insertion}

The strategy of fragment construction and genome manipulation is outlined in Figure 6. The fragments were amplified in three rounds of PCR. In the first round of PCR (Figure 6A), the flanks and the selectable marker are amplified. E. coli chromosome was used as a PCR template to amplify the $5^{\prime}$ flank and the $3^{\prime}$ flank of the target gene. Primers U-F/U-R and L-R/L-F were used to amplify the $5^{\prime}$ homologous arm and the 3 ' homologous arm, respectively. The overlapping marker fragments "tetA-U" and "tetA-L" of the tetA gene were amplified from $\mathrm{pTKS} / \mathrm{CS}$ using T2/T-F and T1/T-R primers, respectively (Additional file 1: Table S1). The 5 'extensions for primers $\mathrm{U}-\mathrm{R}$ and $\mathrm{L}-\mathrm{F}$, containing I-sceI recognition site and $30 \mathrm{bp}$ DR sequence, were complementary to the T-F and T-R primer sequences, respectively. The length of the homologous arms was $250-500$ bp as indicated. The second round of PCR, the 5 ' homologous arm and tet- $\mathrm{U}$, the $3^{\prime}$ homologous arm and tet-L were spliced by SOE-PCR, using primer U-F/T2 and T1/L-R, respectively. The final fragment was constructed using SOE-PCR with primer U-F/L-R and electroporated into target cells carrying pTKRED, according to the method of Kuhlman [52]. Firstly, a linear fragment consisting of tetA cassette flank by duplication regions (DRs) and ISceI recognition sites was used to replace or insert into target site for obtaining an intermediate strain. The tetracycline resistance mutants were selected and confirmed by PCR. Then, arabinose was added to induce ISceI endonuclease expression for cleaving the tet $A$ and facilitating the recombination between DRs. The loss of tet $A$ in the desired recombinant strains were selected on $\mathrm{L}$-arabinose plates and verified by PCR. This method was employed to delete the pgi, edd, eda, insert trc

Table 6 Plasmids used in this study

\begin{tabular}{|c|c|c|}
\hline Plasmid & Characteristics $^{\mathrm{a}}$ & Source \\
\hline pUC18-SVG & pUC18 $P_{\text {vegl }}$-gnd361, Ampr ${ }^{r}, S p c^{r}$ & [13] \\
\hline pUC18-SVZ & pUC18 P $P_{\text {vegl }}-z w f 243$, Ampr', Spc $^{r}$ & [13] \\
\hline $\mathrm{p} 5 \mathrm{C}$ & Expression vector, pSC101 replication, Ptrc, Ampr & Lab collection \\
\hline $\mathrm{p} 15 \mathrm{C}$ & Expression vector, p15A replication, Ptrc, Amp ${ }^{r}$ & Lab collection \\
\hline p20C & Expression vector, pBR322 replication, Ptrc, Amp ${ }^{r}$ & Lab collection \\
\hline p5C-EC10 & pSC101 replication, Amp', $P_{\text {trc }}$-synRBS-ribA-synRBS-ribB- synRBS-ribD-synRBS-ribE-synRBS-ribC & This study \\
\hline p15C-EC10 & p15A replication, Amp ${ }^{r}, P_{\text {trc }}$-synRBS-ribA-synRBS-ribB-synRBS- ribD-synRBS-ribE-synRBS-ribC & This study \\
\hline p20C-EC10 & pBR322 replication, Ampr', $P_{\text {trc }}$-synRBS-ribA-synRBS-ribB- synRBS-ribD-synRBS-ribE-synRBS-ribC & This study \\
\hline p20C-BS15 & pBR322 replication, Ampr', $P_{\text {trc }}$-synRBS-ribB/A-synRBS-ribD-synRBS-ribE-synRBS-ribC & This study \\
\hline p20C-BSrib & pBR322 replication, $A m p^{r}, P_{\text {trc }}-B$ Srib operon & This study \\
\hline p15Trc & Expression vector, p15A replication, $\mathrm{Cm}^{r}$ & Lab collection \\
\hline p15Trc-zg & p15A replication, $\mathrm{Cm}^{r}, \mathrm{P}_{\mathrm{trc}}-\mathrm{SynRBS}-\mathrm{zWf}-\mathrm{synRBS}-\mathrm{gnd}, \mathrm{zwf}$ and gnd genes from C. glutamicum & This study \\
\hline p15Trc-zgp & $\begin{array}{l}\text { p15A replication, } \mathrm{Cm}^{\mathrm{r}} \text {, } \mathrm{P}_{\mathrm{trc}} \text {-synRBS-zwf-synRBS-gnd-synRBS-pgl, zwf and gnd genes from } \\
\text { C. glutamicum, pgl gene from E. coli }\end{array}$ & This study \\
\hline $\mathrm{pTKS} / \mathrm{CS}$ & p15A replication, $\mathrm{Cm}^{r}$, Tet ${ }^{r}$, I-Scel restriction sites & [52] \\
\hline PTKRED & $\begin{array}{l}\text { pSC101 replication, temperature sensitive replication origin, Spcr, } \text { ParaBAD-driven I-Scel gene, }_{\text {Red recombinase expression plasmid, lac-inducible expression }} \\
\text { Red }\end{array}$ & {$[52]$} \\
\hline
\end{tabular}

${ }^{a}$ Abbreviations: Amp ampicillin, $\mathrm{Cm}$ chloramphenicol, $\mathrm{Km}$ kanamycin, Tet tetracycline, $r$ resistance. 


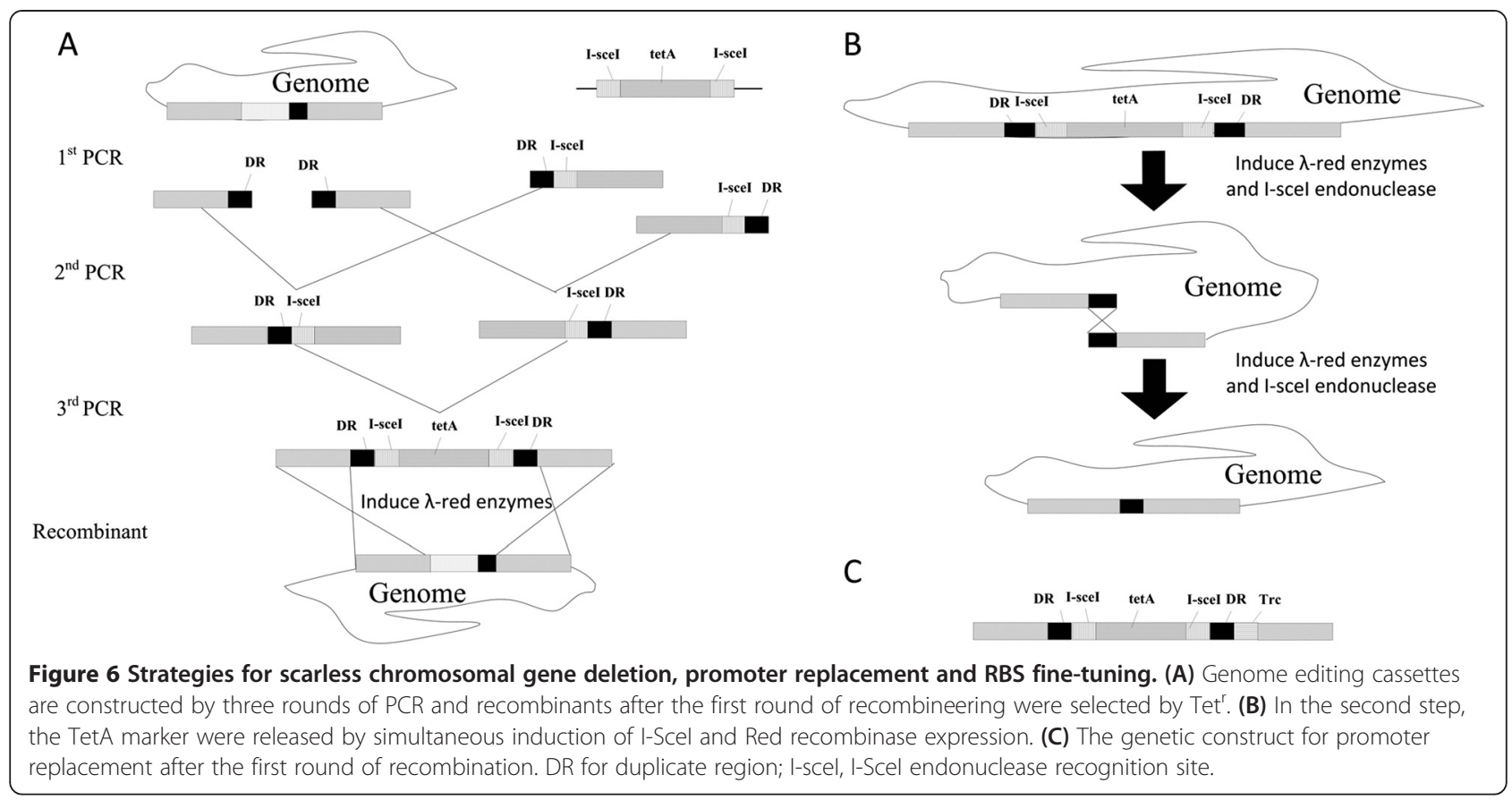

promoter for acs gene, and modulate the expression of ribF. The primers used during construction are listed in Additional file 1: Table S1.

As mentioned above, the strategy of fragment construction and genome manipulation was used to modulate the expression of ribF. The sequence of primer ribF $\mathrm{L}_{-} \mathrm{F}$ is TACAAGGTATACTCGGACGATTTTCACTGTHKTGWR CCAGMCATG. The RBS library of ribF, design with RBS Calculator [42], was placed between the DR sequence (italicized) and the start codon of ribF (bold). The primers used during construction were listed in Additional file 1: Table S1.

\section{Quantitative real-time reverse transcription (RT)-PCR analysis}

The recombinant strains were cultured in LB medium with $1 \%$ glucose. Cells were harvested when OD600 reached 1. Total mRNA were extracted using the RNAprep pure Cell/Bacteria Kit (Tiangen, Beijing, China) as described by the manufacturer. The cDNA was amplified using FastQuant RT Kit (Tiangen, Beijing, China) with the total mRNA as the templates. Samples were then analyzed using a Light Cycler ${ }^{\circ} 480$ II (Roche, Basel, Switzerland) with RealMasterMix (SYBR Green I) (Tiangen, Beijing, China). Quantity real-time PCR amplification primers were listed in Additional file 1: Table S1. The rrsA gene was selected as internal standard for normalization and three biological replicates were performed. The obtained data were analyzed by using the $2^{-\Delta \Delta \mathrm{Ct}}$ method described previously [53].

\section{Enzyme assay and preparation of cell extracts}

The engineering strains were cultivated in LB medium containing $1 \%$ glucose. They were cultured to midexponential phase and the cells were harvested by centrifugation for $10 \mathrm{~min}$ at $12000 \times \mathrm{g}$ and $4^{\circ} \mathrm{C}$, washed twice with $100 \mathrm{mM}$ potassium phosphate ( $\mathrm{pH}$ 7.5)-1 mM dithiothreitol-0.1 mM EDTA. The cells were resuspended and sonicated for $5 \mathrm{~min}$ in an ice bath $(130 \mathrm{~W}$, $20 \mathrm{kHz}$, pulse: $5 \mathrm{~s}$ on; $5 \mathrm{~s}$ off). After centrifugation $\left(13,000 \times \mathrm{g}, 10 \mathrm{~min}, 4^{\circ} \mathrm{C}\right)$, the supernatants were used as cell extracts. When necessary, IPTG was used at a concentration of $2 \mathrm{mM}$ for induction. The activities of GTP cyclohydrolase II, riboflavin synthase and flavokinase activity were measured as previously described [54-56]. The activities of glucose 6-phosphate-1-dehydrogenase and 6-phosphogluconate dehydrogenase were determined as previously described [57]. Total protein concentrations were determined by the Bradford method using bovine serum albumin as standard [58].

\section{Production of riboflavin from glucose}

For riboflavin production, LBG medium (LB medium with $1 \%$ (W/V) glucose), modified M9 medium, or modified minimal salt (MS) medium was selected. An amount of $20 \mathrm{~g} /$ liter glucose or $10 \mathrm{~g} /$ liter glucose was added as the carbon source except as indicated. The modified M9 medium contained (per liter) $6 \mathrm{~g} \mathrm{Na}_{2} \mathrm{HPO}_{4}, 3 \mathrm{~g} \mathrm{K \textrm {H } _ { 2 }} \mathrm{PO}_{4}$, $1 \mathrm{~g} \mathrm{NH}_{4} \mathrm{Cl}, 0.5 \mathrm{~g} \mathrm{NaCl}, 2 \mathrm{mM} \mathrm{MgSO}_{4}, 0.1 \mathrm{mM} \mathrm{CaCl}_{2}$, and yeast extract as indicated. The MS medium contained (per liter) $3.8 \mathrm{~g} \mathrm{Na}_{2} \mathrm{HPO}_{4}, 1.5 \mathrm{~g} \mathrm{KH}_{2} \mathrm{PO}_{4}, 1.0 \mathrm{~g}\left(\mathrm{NH}_{4}\right)_{2} \mathrm{SO}_{4}$, 
$0.2 \mathrm{~g} \mathrm{MgSO}_{4}$, yeast extract as indicated, and $2 \%(\mathrm{v} / \mathrm{v})$ trace element solution as described in previous studies [59].

For fermentation, transformed strains were cultured overnight in $5 \mathrm{ml} \mathrm{LB}$ media at $37^{\circ} \mathrm{C}$, then transferred into $50 \mathrm{ml} \mathrm{LB}$ media with $1 \%(\mathrm{v} / \mathrm{v})$ of the seed culture. This was cultured to mid-exponential phase at $240 \mathrm{rpm}, 37^{\circ} \mathrm{C}$, and frozen at $-80^{\circ} \mathrm{C}$ in $15 \%$ glycerol $(\mathrm{v} / \mathrm{v})$. The inoculum was prepared from frozen seed stocks in LB medium supplemented with $100 \mathrm{mg} / \mathrm{L}$ ampicillin, grown to midexponential phase, and then used to inoculate batch cultures with $1 \%(\mathrm{v} / \mathrm{v})$ of the seed culture, at $37^{\circ} \mathrm{C}$ or $31^{\circ} \mathrm{C}$ as indicated. When appropriate, IPTG was used at a concentration of $2 \mathrm{mM}$ for induction. For each strain, three parallel fermentations were performed.

\section{Analytical methods}

Cell concentration was calculated from OD $600 \mathrm{~nm}$ measurements. Glucose concentration was measured enzymatically using a glucose analyzer (Model-SBA40, Shandong, China). To determine the concentration of acetate, culture samples were centrifuged at $12,000 \times \mathrm{g}$ for $5 \mathrm{~min}$ and the aqueous supernatant used for HPLC analysis on an Agilent 1100 Series HPLC system equipped with an Aminex HPX87H anion exchange column (Bio-Rad Laboratories, Richmond, CA, USA) and refractive index detector. The column was eluted with $5 \mathrm{mM}$ sulfuric acid at a flow rate of $0.4 \mathrm{ml} / \mathrm{min}$. Standards were prepared for acetate for both the refractive index detector, and calibration curves were created. For riboflavin measurements, culture samples were diluted with $0.05 \mathrm{M} \mathrm{NaOH}$ to the linear range of the spectrophotometer and the A444 was immediately measured. The results represented the means \pm S.D. of three independent experiments. Dry cell weight (DCW) was calculated from the optical density at $600 \mathrm{~nm}$ $\left(1 \mathrm{OD}_{600}=0.38 \mathrm{~g} \mathrm{DCW} / \mathrm{L}\right)$.

\section{Additional file}

Additional file 1: Table S1. Primers used in this study. Table S2. Experimental design for evaluating factors influencing biomass and riboflavin production.

\section{Competing interests}

The authors declare that they have no competing interests.

\section{Authors' contributions}

ZQL designed the experiments; ZQL, ZWW, ZBX, and YFL performed the experiments; ZQL, ZWW and TC wrote the manuscript; TC and XMZ supervised the work; and all authors contributed to the discussion of the research. All authors read and approved the final manuscript.

\section{Acknowledgments}

The authors thank Dr. Thomas E. Kuhlman for kindly providing requested plasmids. This work was supported by National 973 Project [2011CBA00804, 2012CB725203]; National Natural Science Foundation of China [NSFC-21176182, NSFC-21206112, NSFC-21390201]; and National High-tech R\&D Program of China [2012AA02A702, 2012AA022103].

\section{Author details}

'Department of Biochemical Engineering, School of Chemical Engineering and Technology, Tianjin University, Tianjin 300072, People's Republic of China. ${ }^{2}$ Key Laboratory of Systems Bioengineering, Ministry of Education, Tianjin University, Tianjin 300072, People's Republic of China. ${ }^{3}$ Collaborative Innovation Center of Chemical Science and Engineering (Tianjin), Tianjin University, Tianjin 300072, People's Republic of China.

Received: 14 May 2014 Accepted: 9 July 2014

Published: 16 July 2014

\section{References}

1. Massey $\mathrm{V}$ : The chemical and biological versatility of riboflavin. Biochem Soc Trans 2000, 28:283-296.

2. Bornemann S: Flavoenzymes that catalyse reactions with no net redox change. Nat Prod Rep 2002, 19:761-772.

3. Stahmann KP, Revuelta JL, Seulberger H: Three biotechnical processes using Ashbya gossypii, Candida famata, or Bacillus subtilis compete with chemical riboflavin production. Appl Microbiol Biotechnol 2000, 53:509-516.

4. Bacher A, Eberhardt S, Fischer M, Kis K, Richter G: Biosynthesis of vitamin b2 (riboflavin). Annu Rev Nutr 2000, 20:153-167.

5. Abbas CA, Sibirny AA: Genetic control of biosynthesis and transport of riboflavin and flavin nucleotides and construction of robust biotechnological producers. Microbiol Mol Biol Rev 2011, 75:321-360.

6. Hümbelin M, Griesser V, Keller T, Schurter W, Haiker M, Hohmann HP, Ritz H, Richter G, Bacher A, van Loon APGM: GTP cyclohydrolase II and 3,4-dihydroxy-2-butanone 4-phosphate synthase are rate-limiting enzymes in riboflavin synthesis of an industrial Bacillus subtilis strain used for riboflavin production. J Ind Microbiol Biotechnol 1999, 22:1-7.

7. Perkins JB, Sloma A, Hermann T, Theriault K, Zachgo E, Erdenberger T, Hannett N, Chatterjee NP, Williams V II, Rufo GA Jr, Hatch R, Pero J: Genetic engineering of Bacillus subtilis for the commercial production of riboflavin. J Ind Microbiol Biotechnol 1999, 22:8-18.

8. Zamboni N, Mouncey N, Hohmann H-P, Sauer U: Reducing maintenance metabolism by metabolic engineering of respiration improves riboflavin production by Bacillus subtilis. Metab Eng 2003, 5:49-55.

9. Li XJ, Chen T, Chen X, Zhao XM: Redirection electron flow to high coupling efficiency of terminal oxidase to enhance riboflavin biosynthesis. Appl Microbiol Biotechnol 2006, 73:374-383.

10. Dauner M, Sonderegger M, Hochuli M, Szyperski T, Wuthrich K, Hohmann HP, Sauer U, Bailey JE: Intracellular carbon fluxes in riboflavin-producing Bacillus subtilis during growth on two-carbon substrate mixtures. Appl Environ Microbiol 2002, 68:1760-1771.

11. Zamboni N, Maaheimo H, Szyperski T, Hohmann HP, Sauer U: The phosphoenolpyruvate carboxykinase also catalyzes C3 carboxylation at the interface of glycolysis and the TCA cycle of Bacillus subtilis. Metab Eng 2004, 6:277-284.

12. Zhu Y, Chen $X$, Chen T, Shi S, Zhao X: Over-expression of glucose dehydrogenase improves cell growth and riboflavin production in Bacillus subtilis. Biotechnol Lett 2006, 28:1667-1672.

13. Wang ZW, Chen T, Ma XH, Shen Z, Zhao XM: Enhancement of riboflavin production with Bacillus subtilis by expression and site-directed mutagenesis of zwf and gnd gene from Corynebacterium glutamicum. Bioresour Technol 2011, 102:3934-3940.

14. Duan YX, Chen T, Chen X, Zhao XM: Overexpression of glucose-6-phosphate dehydrogenase enhances riboflavin production in Bacillus subtilis. Appl Microbiol Biotechnol 2010, 85:1907-1914.

15. Tannler S, Zamboni N, Kiraly C, Aymerich S, Sauer U: Screening of Bacillus subtilis transposon mutants with altered riboflavin production. Metab Eng 2008, 10:216-226.

16. Shi $S$, Chen $T$, Zhang $Z$, Chen $X$, Zhao $X$ : Transcriptome analysis guided metabolic engineering of Bacillus subtilis for riboflavin production. Metab Eng 2009, 11:243-252.

17. Shi S, Shen Z, Chen X, Chen T, Zhao X: Increased production of riboflavin by metabolic engineering of the purine pathway in Bacillus subtilis. Biochem Eng J 2009, 46:28-33.

18. Zhang F, Rodriguez S, Keasling JD: Metabolic engineering of microbial pathways for advanced biofuels production. Curr Opin Biotechnol 2011, 22:775-783. 
19. Flores N, Xiao J, Berry A, Bolivar F, Valle F: Pathway engineering for the production of aromatic compounds in Escherichia coli. Nat Biotechnol 1996, 14:620-623.

20. Wendisch VF, Bott M, Eikmanns BJ: Metabolic engineering of Escherichia coli and Corynebacterium glutamicum for biotechnological production of organic acids and amino acids. Curr Opin Microbiol 2006, 9:268-274.

21. Marx H, Mattanovich D, Sauer M: Overexpression of the riboflavin biosynthetic pathway in Pichia pastoris. Microb Cell Fact 2008, 7:23.

22. Dmytruk KV, Yatsyshyn VY, Sybirna NO, Fedorovych DV, Sibirny AA: Metabolic engineering and classic selection of the yeast Candida famata (Candida flareri) for construction of strains with enhanced riboflavin production. Metab Eng 2011, 13:82-88.

23. Birkenmeier M, Neumann S, Roder T: Kinetic modeling of riboflavin biosynthesis in Bacillus subtilis under production conditions. Biotechnol Lett 2014, 36:919-928.

24. Sklyarova SA, Kreneva RA, Perumov DA, Mironov AS: The characterization of internal promoters in the Bacillus subtilis riboflavin biosynthesis operon. Russ J Genet 2012, 48:967-974.

25. Becker J, Klopprogge C, Herold A, Zelder O, Bolten CJ, Wittmann C: Metabolic flux engineering of L-lysine production in Corynebacterium glutamicum-over expression and modification of G6P dehydrogenase. J Biotechnol 2007, 132:99-109.

26. Ohnishi J, Katahira R, Mitsuhashi S, Kakita S, Ikeda M: A novel gnd mutation leading to increased L-lysine production in Corynebacterium glutamicum. FEMS Microbiol Lett 2005, 242:265-274.

27. Thomason LC, Court DL, Datta AR, Khanna R, Rosner JL: Identification of the Escherichia coli K-12 ybhE gene as pgl, encoding 6phosphogluconolactonase. J Bacteriol 2004, 186:8248-8253.

28. Wang Y, Wu SL, Hancock WS, Trala R, Kessler M, Taylor AH, Patel PS, Aon JC: Proteomic profiling of Escherichia coli proteins under high cell density fed-batch cultivation with overexpression of phosphogluconolactonase Biotechnol Prog 2005, 21:1401-1411.

29. Ishii N, Nakahigashi K, Baba T, Robert M, Soga T, Kanai A, Hirasawa T, Naba M, Hirai K, Hoque A, Ho PY, Kakazu Y, Sugawara K, Igarashi S, Harada S, Masuda T, Sugiyama N, Togashi T, Hasegawa M, Takai Y, Yugi K, Arakawa K, Iwata N, Toya Y, Nakayama Y, Nishioka T, Shimizu K, Mori H, Tomita M: Multiple high-throughput analyses monitor the response of $E$. coli to perturbations. Science 2007, 316:593-597.

30. Schweder T, Lin HY, Jurgen B, Breitenstein A, Riemschneider S, Khalameyzer V, Gupta A, Buttner K, Neubauer P: Role of the general stress response during strong overexpression of a heterologous gene in Escherichia coli. Appl Microbiol Biotechnol 2002, 58:330-337.

31. Hua Q, Yang C, Baba T, Mori H, Shimizu K: Responses of the Central Metabolism in Escherichia coli to Phosphoglucose Isomerase and Glucose-6-Phosphate Dehydrogenase Knockouts. J Bacterio/ 2003, 185:7053-7067.

32. Siedler S, Bringer S, Blank LM, Bott M: Engineering yield and rate of reductive biotransformation in Escherichia coli by partial cyclization of the pentose phosphate pathway and PTS-independent glucose transport. Appl Microbiol Biotechnol 2012, 93:1459-1467.

33. Morita T, El-Kazzaz W, Tanaka Y, Inada T, Aiba H: Accumulation of glucose 6-phosphate or fructose 6-phosphate is responsible for destabilization of glucose transporter mRNA in Escherichia coli. J Biol Chem 2003, 278:15608-15614.

34. Toya $Y$, Ishii N, Nakahigashi K, Hirasawa T, Soga T, Tomita M, Shimizu K. 13C-metabolic flux analysis for batch culture of Escherichia coli and its Pyk and Pgi gene knockout mutants based on mass isotopomer distribution of intracellular metabolites. Biotechnol Prog 2010, 26:975-992.

35. Fraenkel DG, Levisohn SR: Glucose and gluconate metabolism in an Escherichia coli mutant lacking phosphoglucose isomerase. J Bacteriol 1967, 93:1571-1578.

36. Fong SS, Nanchen A, Palsson BO, Sauer U: Latent pathway activation and increased pathway capacity enable Escherichia coli adaptation to loss of key metabolic enzymes. J Biol Chem 2006, 281:8024-8033.

37. Kabir MM, Shimizu K: Gene expression patterns for metabolic pathway in pgi knockout Escherichia coli with and without phb genes based on RT-PCR. J Biotechnol 2003, 105:11-31.

38. Lin H, Castro NM, Bennett GN, San KY: Acetyl-CoA synthetase overexpression in Escherichia coli demonstrates more efficient acetate assimilation and lower acetate accumulation: a potential tool in metabolic engineering. App/ Microbiol Biotechnol 2006, 71:870-874.
39. Mack M, van Loon AP, Hohmann HP: Regulation of riboflavin biosynthesis in Bacillus subtilis is affected by the activity of the flavokinase/flavin adenine dinucleotide synthetase encoded by ribC. J Bacterio/ 1998, 180:950-955.

40. Fischer M, Schott AK, Romisch W, Ramsperger A, Augustin M, Fidler A, Bacher A, Richter G, Huber R, Eisenreich W: Evolution of vitamin B2 biosynthesis. A novel class of riboflavin synthase in Archaea. J Mol Biol 2004, 343:267-278.

41. Baba T, Ara T, Hasegawa M, Takai Y, Okumura Y, Baba M, Datsenko KA, Tomita M, Wanner BL, Mori H: Construction of Escherichia coli K-12 in-frame, single-gene knockout mutants: the Keio collection. Mol Syst Biol 2006, 2:2006. 0008 .

42. Salis HM: The ribosome binding site calculator. Methods Enzymol 2011, 498:19-42.

43. Gadgil M, Kapur V, Hu WS: Transcriptional response of Escherichia coli to temperature shift. Biotechnol Prog 2005, 21:689-699.

44. Zhang Y, Taiming L, Liu J: Low temperature and glucose enhanced T7 RNA polymerase-based plasmid stability for increasing expression of glucagon-like peptide-2 in Escherichia coli. Protein Expr Purif 2003, 29:132-139.

45. Plaut GW: Biosynthesis of riboflavin. I. Incorporation of C14-labeled compounds into rings B and C. J Biol Chem 1954, 208:513-520.

46. Monschau N, Sahm H, Stahmann K: Threonine aldolase overexpression plus threonine supplementation enhanced riboflavin production in Ashbya gossypii. Appl Environ Microbiol 1998, 64:4283-4290.

47. Dmytruk K, Lyzak O, Yatsyshyn V, Kluz M, Sibirny V, Puchalski C, Sibirny A: Construction and fed-batch cultivation of Candida famata with enhanced riboflavin production. J Biotechnol 2014, 172:11-17.

48. Jimenez A, Santos MA, Pompejus M, Revuelta JL: Metabolic engineering of the purine pathway for riboflavin production in Ashbya gossypii. Appl Environ Microbiol 2005, 71:5743-5751.

49. Jimenez A, Santos MA, Revuelta JL: Phosphoribosyl pyrophosphate synthetase activity affects growth and riboflavin production in Ashbya gossypii. BMC Biotechnol 2008, 8:67.

50. Horton RM, Hunt HD, Ho SN, Pullen JK, Pease LR: Engineering hybrid genes without the use of restriction enzymes: gene splicing by overlap extension. Gene 1989, 77:61-68.

51. Quan J, Tian J: Circular polymerase extension cloning of complex gene libraries and pathways. PLoS One 2009, 4:e6441.

52. Kuhlman TE, Cox EC: Site-specific chromosomal integration of large synthetic constructs. Nucleic Acids Res 2010, 38:e92.

53. Livak KJ, Schmittgen TD: Analysis of relative gene expression data using real-time quantitative PCR and the 2(-Delta Delta $C(T)$ ) Method. Methods 2001, 25:402-408.

54. Ritz H, Schramek N, Bracher A, Herz S, Eisenreich W, Richter G, Bacher A: Biosynthesis of riboflavin: studies on the mechanism of GTP cyclohydrolase II. J Biol Chem 2001, 276:22273-22277.

55. Illarionov B, Kemter K, Eberhardt S, Richter G, Cushman M, Bacher A: Riboflavin synthase of Escherichia coli. Effect of single amino acid substitutions on reaction rate and ligand binding properties. $J \mathrm{Bio} / \mathrm{Chem}$ 2001, 276:11524-11530.

56. Bandyopadhyay D, Chatterjee AK, Datta AG: Effect of cadmium, mercury and copper on partially purified hepatic flavokinase of rat. Mol Cell Biochem 1997, 167:73-80.

57. Peng L, Shimizu K: Global metabolic regulation analysis for Escherichia coli K12 based on protein expression by 2-dimensional electrophoresis and enzyme activity measurement. Appl Microbiol Biotechnol 2003, 61:163-178.

58. Bradford MM: A rapid and sensitive method for the quantitation of microgram quantities of protein utilizing the principle of protein-dye binding. Anal Biochem 1976, 72:248-254.

59. Qiu YZ, Han J, Guo JJ, Chen GQ: Production of poly(3-hydroxybutyrate-co-3hydroxyhexanoate) from gluconate and glucose by recombinant Aeromonas hydrophila and Pseudomonas putida. Biotechnol Lett 2005, 27:1381-1386.

\section{doi:10.1186/s12934-014-0104-5}

Cite this article as: Lin et al:: Metabolic engineering of Escherichia coli for the production of riboflavin. Microbial Cell Factories 2014 13:104. 